\section{Rasmussen vindicated?}

The Three Mile Island accident might have been prevented if more attention had been paid to a report on nuclear risk, but its message was clouded by disputes. David Dickson reports

ONE unexpected spin-off from the accident at the Three Mile Island nuclear plant last March has been a shift in attitude towards a report on the safety of nuclear reactors published in 1975 - the much-criticised Rasmussen Report.

Known officially as Wash 1400 , and commissioned by the Nuclear Regulatory Commission, the report is usually referred to under the name of its principal author Dr Norman Rasmussen, now professor of nuclear engineering at the Massachusetts Institute of Technology.

When the report first appeared, the nuclear industry made much of the report's conclusion that the level of risk associated with nuclear power was relatively low compared to other energy sources. But it also received a barrage of criticism, in particular over the validity of broad conclusions drawn from limited data.

Much of this criticism was subsequently endorsed by a review committee established by the NRC, which repudiated some key sections. But the report of the President's Commission on the TMI accident, chaired by Dr John Kemeny and released two weeks ago, points out that the sequence of events leading to the accident supports Rasmussen's general analysis with the implication that if more attention had been paid to the positive aspects of the report, the accident might have been avoided.

Professor Rasmussen is unapologetic about the report. He accepts that some aspects of the accident, in particular the extent of its psychological impact, were not predicted. But he points out that the report emphasises the dangers of concentrating safety planning on single major equipment failures, rather than on an accumulation of relatively minor failures compounded by operator error. "If anything, we were too conservative. We said that if the temperatures in the core went as high as they did, then we did not know if it would melt or not, but said it might have done. In the event the core did not melt, though a few more human errors would have caused it to do so."

Part of the problem is that there are, in a sense, two Rasmussen reports. The first is a detailed application of fault-tree/eventtree analysis to equipment failures in nuclear power plants. Even critics acknowledge this as an important contribution towards understanding risks. And the NRC review, carried out by a committee under Professor $\mathrm{H}$ W Lewis of the University of California, stated that the methodology developed "both can and should be more widely used by the NRC'"

The second version of the report, however, is the one that was presented through the news media as carrying the principal message that nuclear power is basically safe. This conclusion, for example, helped persuade Congress to accept the Price-Anderson Act, limiting the liability of power companies in the case of nuclear accidents.

Professor Rasmussen is himself critical of those who over-sell the safety of nuclear power. "In the past there was a general tendency of public relations people to under-estimate the intelligence of the public, leading to the feeling that it was statements rather than realistically portraying the risks and benefits of nuclear power. As the facts have evolved, however, the nuclear supporters have lost credibility, and many of their arguments are no longer believed."

Credibility has been at the heart of arguments over the Rasmussen Report itself. The Lewis Committee, following the lead of groups such as the Union of Concerned Scientists, criticised in particular the error bounds placed on the probabilities of various accident sequences.

They argued that these bounds were greatly understated, partly because of an inadequate data base, and partly because of an inability to quantify "common cause" failures, such as fire and earthquakes.

Professor Rasmussen defends his judgment. "I disagree with the Lewis Committee about margins of error. They found that the uncertainty was understated. I say that it might be understated in the safe direction, but I do not think it was greatly understated in the unsafe direction, because we already have 600 plant years of operating experience, and we have not melted a core. This gives an upper bound which is $\mathbf{3 0}$ times higher than ours".

It was the debates over the limits of uncertainty that led to the widest public criticism of the report. The NRC, for example, earlier this year issued a statement emphasising that as a result of its review "It does not regard as reliable the reactor safety study's numerical estimate of the overall risk of reactor accident."

Ironically, the vulnerability of the probability analysis seems to have resulted in that part of the report which was supported by the Lewis Review not getting the attention that it deserved.

A report prepared by the technical staff of the Kemeny Commission says that Wash 1400 contained three important messages. These involved the expected frequency of accidents (the TMI accident was well within the predicted range), methods for improving reactor safety through, for example, the use of fault-tree analysis to identify weak links, and the most likely types of accidents. sufficient to issue warm pacifying

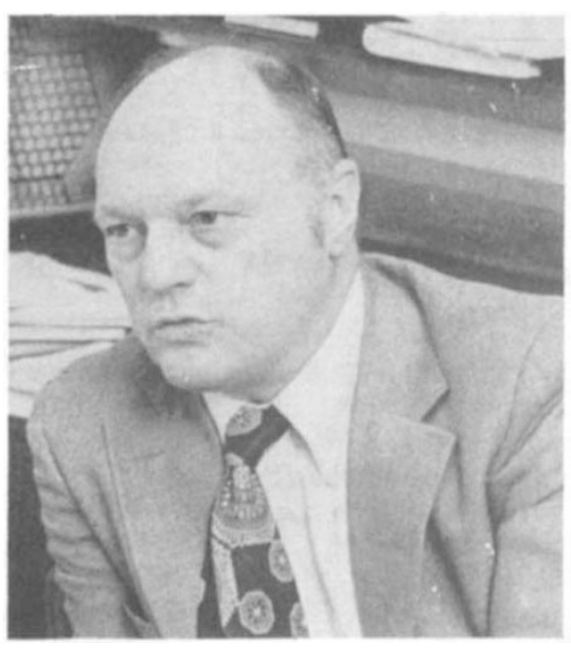

Rasmussen: unapologetic about the report

"Perhaps it is a fault of the report that these messages were not emphasised, because the conclusion most often associated with Wash 1400 - reactors are safe - receives the primary emphasis in the report. Perhaps it was the fault of the NRC that more effort was dedicated to criticising Wash 1400 than was applied to understanding its messages," the technical report (which does not necessarily reflect the Commission's views) says.

Rasmussen's critics argue that the construction of the report made it directly vulnerable to lop-sided interpretation. According to Dr Frank von Hippel of Princeton University, many scientists who read the executive summary of the report - also criticised by the Lewis Committee _. "were infuriated by its Madison Avenue tone."

"If you follow the report backwards, from the appendices to the report itself to the executive summary, you find that at each level the qualifications and uncertainties of the previous level are dropped, so that what comes out is misleading because of what is omitted,"' he says.

Professor Rasmussen accepts some of the Lewis criticisms - but repeats that the TMI accident underlines the report's main conclusions. "The anti-nuclear people were able to use the accident to their advantage. But you can draw some satisfaction for both sides. Utility operators are now more prepared to listen to suggestions about safety than they were before, and on both the regulatory and the operating side, the event will lead to substantially reduced risk."

The accident had done nothing to change his support for nuclear power, a position now frequently expressed on public platforms. "Every new technology, when it was poorly understood, has attracted its doomsday prophets. Mostly this opposition has died away, and I suspect that nuclear power will probably go the same way. If we do not go on building nuclear plants, we will soon have major problems with the reliability of our power supply." 